\title{
Abiotic Stresses Affect Trichoderma harzianum T39-Induced Resistance to Downy Mildew in Grapevine
}

\author{
Benedetta Roatti, Michele Perazzolli, Cesare Gessler, and Ilaria Pertot
}

First, second, and fourth authors: Department of Sustainable Agro-Ecosystems and Bioresources, Research and Innovation Centre, Fondazione Edmund Mach (FEM), Via E. Mach 1, 38010 S. Michele all'Adige, Italy; and first and third authors: Institute of Integrative Biology, ETH Zürich, 8092 Zürich.

Accepted for publication 14 June 2013.

\begin{abstract}
Roatti, B. Perazzolli, M., Gessler, C., and Pertot, I. 2013. Abiotic stresses affect Trichoderma harzianum T39-induced resistance to downy mildew in grapevine. Phytopathology 103:1227-1234.

Enhancement of plant defense through the application of resistance inducers seems a promising alternative to chemical fungicides for controlling crop diseases but the efficacy can be affected by abiotic factors in the field. Plants respond to abiotic stresses with hormonal signals that may interfere with the mechanisms of induced systemic resistance (ISR) to pathogens. In this study, we exposed grapevines to heat, drought, or both to investigate the effects of abiotic stresses on grapevine resistance induced by Trichoderma harzianum T39 (T39) to

downy mildew. Whereas the efficacy of T39-induced resistance was not affected by exposure to heat or drought, it was significantly reduced by combined abiotic stresses. Decrease of leaf water potential and upregulation of heat-stress markers confirmed that plants reacted to abiotic stresses. Basal expression of defense-related genes and their upregulation during T39-induced resistance were attenuated by abiotic stresses, in agreement with the reduced efficacy of T39. The evidence reported here suggests that exposure of crops to abiotic stress should be carefully considered to optimize the use of resistance inducers, especially in view of future global climate changes. Expression analysis of ISR marker genes could be helpful to identify when plants are responding to abiotic stresses, in order to optimize treatments with resistance inducers in field.
\end{abstract}

Grapevines are often exposed to environmental stresses, which may alter their physiological status and affect proper development (7). High temperatures and water deficiency are significant factors limiting plant growth and productivity under field conditions (10). Moreover, global climate change is expected to bring about increased temperatures and reductions in precipitation in several areas of the world $(24,28)$, increasing the risk for heat and drought stresses in plants $(19,27)$. Plants have evolved complex systems to defend themselves against abiotic stresses. The cellular processes triggered in response to abiotic stresses take place in all plant organs and are mostly driven by abscisic acid (ABA) signaling (14). During their life cycle, plants are also subjected to biotic stresses, such as pathogens and insect attacks. The signaling molecules involved in these defense responses are mainly salicylic acid (SA), jasmonic acid (JA), and ethylene (ET) (43). The protective responses of plants exposed to biotic and abiotic stresses are quite complex, and the signaling pathways interact synergistically and antagonistically with each other $(5,21)$. Greater knowledge of the effect of abiotic stresses and ABA signaling on plant-pathogen interactions was gained in recent times $(2,17$, $33,48,52,63)$, and evidence indicated that ABA interferes with plant defense responses to both necrotrophic and biotrophic pathogens $(4,5,20,48)$. Therefore, the function of ABA is not limited to the regulation of environmental stresses but also tunes many plant processes involving both biotic and abiotic stimuli (4). In general, plants respond differently to multiple stresses than to

Corresponding author: M. Perazzolli;

E-mail address: michele.perazzolli@fmach.it

* The $e$-Xtra logo stands for "electronic extra" and indicates that the online version contains one supplemental table.

http://dx.doi.org/10.1094/PHYTO-02-13-0040-R

(C) 2013 The American Phytopathological Society individual stresses (5), indicating that environmental stresses should be taken into account in order to clearly understand plant defense responses to pathogens.

Downy mildew, caused by the biotrophic oomycete Plasmopara viticola (Berk. \& M. A. Curtis) Berl. \& De Toni, is one of the most destructive diseases of grapevine (22). Plants are treated with chemical fungicides throughout the growing season to avoid substantial yield losses (22). In an effort to reduce the use of chemicals, interest has recently focused on alternative approaches, such as methods based on the enhancement of plant defense $(22,55)$. This process relies on the ability of beneficial microorganisms to improve plant self-protection by activating a defense mechanism known as induced systemic resistance (ISR) (42). ISR can be activated by applying beneficial microorganisms to leaves or roots $(37,44)$ and it is usually regulated by JA- and ETdependent signaling pathways (42). ISR is commonly associated with enhanced defense reaction upon pathogen inoculation, also known as priming (12). Application of the ascomycete Trichoderma harzianum strain T39 (T39) has been shown to reduce downy mildew symptoms locally and systemically without direct toxic effects on $P$. viticola sporangia, demonstrating that the mechanism of action of T39 to downy mildew was mediated by resistance induction in grapevine (37). T39-induced resistance involves JA and ET signaling pathways (26) and does not have negative effects on shoot growth, leaf dimension, and chlorophyll content, indicating no energy cost for grapevines (39). T39induced resistance is based on complex reprogramming of the leaf transcriptome and proteome, with direct activation of the microbial recognition machinery and enhanced expression of defenserelated processes after downy mildew inoculation $(34,38)$. In particular, T39-induced resistance partially inhibits some diseaserelated processes and specifically activates defense mechanisms known to be involved in the reaction of resistant genotypes to downy mildew (38). Moreover, histological analysis indicated that T39 primes grapevine defenses for enhanced accumulation of 
callose in stomata guard cells and production of reactive oxygen species (ROS) in leaf tissues upon $P$. viticola inoculation (34).

Activation of ISR through application of beneficial microorganisms appears to be a promising method for the biological control of crop diseases (55). However, disease control mediated by ISR is often inconsistent and only partially effective under field conditions, and employment of this biocontrol tool in agriculture is far from widespread $(22,61,62)$. ISR is a plant response regulated by a complex crosstalk of hormonal signaling (42) and it is likely to be affected by environmental conditions and exposure of plants to abiotic stresses (60-62). Greater knowledge of the ISR efficacy in plants exposed to various abiotic conditions is particularly important to further implement the use of resistance inducers in plant-protection strategies under field conditions (60$62)$. The aim of this study was to investigate the effect of short exposure of grapevine plants to heat and drought stress on the level of resistance induced by T39 treatment against downy mildew. Our physiological and molecular analysis showed that T39induced resistance was negatively affected by exposure of plants to combined abiotic stresses, suggesting that environmental conditions should be carefully considered to further optimize the use of resistance inducers in vineyards, especially in view of future climate changes.

\section{MATERIALS AND METHODS}

Exposure of grapevines to heat and drought stress. Twoyear-old plants of the susceptible grapevine Vitis vinifera 'Pinot Noir' grafted onto 'Kober 5BB' were planted in individual 2.5liter pots containing a mixture of peat and pumice (3:1). Plants were grown in the greenhouse at $25 \pm 1{ }^{\circ} \mathrm{C}$ with a relative humidity (RH) of $60 \pm 10 \%$ for 2 months. Plants were then incubated for 14 days under the following temperature and irrigation conditions: unstressed (NS: irrigation at field capacity every 2 days at $25 \pm 1{ }^{\circ} \mathrm{C}$ ), drought stress (no irrigation at $25 \pm 1{ }^{\circ} \mathrm{C}$ ), heat stress (daily irrigation at field capacity at $35 \pm 1^{\circ} \mathrm{C}$ ), and combined heat and drought stress (HDS, daily irrigation with $50 \mathrm{ml}$ of water at $35 \pm 1^{\circ} \mathrm{C}$ ). HDS plants were irrigated with this small amount of water to prevent wilting. $\mathrm{RH}$ was $60 \pm 10 \%$ at $25^{\circ} \mathrm{C}$ and $50 \pm 10 \%$ at $35^{\circ} \mathrm{C}$.

Analysis of soil moisture, leaf water potential, and leaf chlorophyll content. Soil water content was measured with a Time Domain Reflectometry (TDR) portable meter (Field Scout TDR 200 Soil Moisture Probe; Spectrum Technologies) as volumetric water content. TDR exploits the electrical conductivity of the soil solution (which varies as a function of soil moisture) to calculate the volumetric water content of the soil, expressed as a percentage. Volumetric water content of each pot was measured daily at the same time using $15-\mathrm{cm}$ rods to monitor the irrigation scheduling.

At mid-morning ( $4 \mathrm{~h}$ after light onset), total leaf water potential $\left(\Psi_{\text {leaf }}\right)$ was measured using a Scholander-type pressure chamber (Soil Moisture Equipment Corp, Santa Barbara, CA) according to Lovisolo et al. (30). Measurements were taken from 10:00 to 11:30 hours (solar time) under a light intensity (photosynthetic active radiation) of $30 \mu \mathrm{mol} \mathrm{m} \mathrm{m}^{-2} \mathrm{~s}^{-1}$, at the beginning (day 1) and at the end (day 14) of the stressing period. Four plants per growth condition were randomly selected. In each plant, $\Psi_{\text {leaf }}$ was measured in three mature primary leaves detached from the fourth, fifth, and sixth node starting from the apical meristem. Each leaf was put into a plastic bag prior to excision and assessed within $30 \mathrm{~s}$ (46). Mean $\Psi_{\text {leaf }}$ was calculated for each plant and mean $\Psi_{\text {leaf }}$ was calculated for each growth condition.

Quantitative assessment of the early stages of plant stress was evaluated by estimating chlorophyll content (51). A nondestructive SPAD meter (SPAD-502, Minolta Camera Co., Osaka, Japan) was used, and leaf transmittance was measured $4 \mathrm{~h}$ after light onset on three leaves of each plant (from the fourth, fifth, and sixth node starting from the apical meristem) at the beginning (day 1) and on day 11 of the stressing period. Leaf chlorophyll content was then obtained by converting SPAD measures in milligrams of chlorophyll per square meter of leaf area $\left(\mathrm{mg} \mathrm{m}^{-2}\right)$, according to the relationship optimized for grapevine leaves (51).

Resistance induction and control treatments. T39 was grown for 2 weeks at $25^{\circ} \mathrm{C}$ on $100 \mathrm{~g}$ of twice-sterilized rice grains (29). A conidia suspension was obtained by washing the colonized rice grains in distilled water. The rice grains were filtered out with a fine net and the suspension was adjusted to $1 \times 10^{7}$ conidia $\mathrm{ml}^{-1}$ by counting with a hemocytometer under a light microscope. Plants were sprayed with the T39 conidia suspension to induce resistance against $P$. viticola (39), and control plants were treated with distilled water (control). Treatments started on day 11 of the experiment and were repeated daily for three consecutive days (1, 2 , and 3 days before $P$. viticola inoculation) in order to induce a high level of phenotypic resistance response $(37,39)$. Treatments were applied with a compressed-air hand sprayer to the abaxial and adaxial surfaces of all leaves; 20 to $30 \mathrm{ml}$ was applied to each plant, depending on the number of leaves. Nine replicates (plants) per treatment per growth condition were analyzed in a randomized complete block design and the experiment was carried out twice.

Pathogen inoculation, assessment of disease severity, and efficacy of T39-induced resistance. A $P$. viticola isolate was collected from an untreated vineyard in Trentino (northern Italy) and maintained by subsequent inoculations on $V$. vinifera 'Pinot Noir' plants under greenhouse conditions. Fresh sporangia were obtained by placing plants with oil spot symptoms in the dark overnight at 99 to $100 \% \mathrm{RH}$ and $25 \pm 1^{\circ} \mathrm{C}$. Sporangia were then collected by washing the leaves bearing sporulating lesions with cold $\left(5^{\circ} \mathrm{C}\right)$ distilled water. The concentration of the inoculum suspension was adjusted to $1 \times 10^{5}$ sporangia $\mathrm{ml}^{-1}$ by counting with a hemocytometer under a light microscope.

The day after the last treatment, abaxial leaf surfaces were inoculated with $P$. viticola using a compressed-air hand sprayer. Inoculum suspension (20 to $30 \mathrm{ml}$, depending on the number of leaves) was sprayed onto each plant. The time point at which the plants were inoculated coincided with the end of the stressing period. Inoculated plants were incubated overnight in the dark at $25 \pm 1{ }^{\circ} \mathrm{C}$ and 99 to $100 \% \mathrm{RH}$ (inoculum conditions), and then maintained under controlled greenhouse conditions at $25 \pm 1^{\circ} \mathrm{C}$ and $60 \pm 10 \%$ RH. Six replicates (plants) per treatment per growth condition were inoculated in a randomized complete block design, while the remaining three plants were incubated overnight in the inoculum conditions without being inoculated.

Six days after pathogen inoculation, plants were incubated overnight in the dark at $25 \pm 1^{\circ} \mathrm{C}$ with 99 to $100 \% \mathrm{RH}$ to promote downy mildew sporulation. Severity of downy mildew was assessed visually on all leaves of each plant, according to the standard guidelines of the European and Mediterranean Plant Protection Organisation (18) (http://pp1.eppo.int/list.php). For each leaf, disease severity was expressed as the proportion (percentage of 0 to $100 \%$, with intervals of $5 \%$ ) of abaxial leaf area covered by white sporulation of $P$. viticola in relation to the total leaf area, and a mean value was calculated for each plant $(13,32)$. Induced resistance was evaluated by analyzing the reduction of disease severity on leaves previously treated with the resistance inducer, and the efficacy of the treatment was calculated for each growth condition according to the following equation: efficacy = (severity of control plants - severity of T39-treated plants)/severity of control plants $\times 100$. The experiment was carried out twice.

Leaf sample collection and gene expression analysis. Leaf samples from T39-treated and control plants under the NS and HDS conditions were collected immediately before $P$. viticola inoculation (uninoculated samples at $0 \mathrm{~h}$ ), which corresponded to the end of the stressing period. Leaf samples were also collected at $24 \mathrm{~h}$ after $P$. viticola inoculation from inoculated plants (inocu- 
lated samples at $24 \mathrm{~h}$ ) and from uninoculated plants maintained under the inoculum conditions (uninoculated samples at $24 \mathrm{~h}$ ). Three plants (replicates) per time point were sampled for each treatment per growth condition. Each sample comprised three half-leaves from the same plant, and only leaves of the fourth, fifth, and sixth node starting from the apical meristem were collected, pooled, and immediately frozen in liquid nitrogen and stored at $-80^{\circ} \mathrm{C}$.

Total RNA was extracted from the frozen samples using the Spectrum Plant Total RNA kit (Sigma-Aldrich, St. Louis) and quantified by NanoDrop 8000 (Thermo Fisher Scientific, Wilmington, DE). RNA was treated with DNase I (Invitrogen, Carlsbad, CA), and the first-strand cDNA was synthesized from $1.0 \mu \mathrm{g}$ of total RNA using Superscript III (Invitrogen) and oligodT primer. Quantitative real-time polymerase chain reaction (qPCR) reactions were carried out with Platinum SYBR Green qPCR SuperMix-UDG (Invitrogen) and specific primers (Table 1) using the Light Cycler 480 (Roche Diagnostics, Mannheim, Germany). The PCR conditions were $50^{\circ} \mathrm{C}$ for 2 min and $95^{\circ} \mathrm{C}$ for $2 \mathrm{~min}$ as initial steps, followed by 50 cycles of $95^{\circ} \mathrm{C}$ for $15 \mathrm{~s}$ and $60^{\circ} \mathrm{C}$ for $1 \mathrm{~min}$. Each sample was examined in three technical replicates and dissociation curves were analyzed to verify the specificity of each amplification reaction. Cycle threshold values were extracted with the Light Cycler 480 SV1.5.0 software (Roche Diagnostics) using the second derivative calculation, and reaction efficiency was calculated with the LinRegPCR 11.1 software (49). The relative expression of each gene was obtained according to the Pfaffl equation (41) using Actin as reference gene, with constitutive expression for normalization $(38,45)$. Relative expression values were calculated using NS uninoculated control plants at $0 \mathrm{~h}$ as the calibrator for gene expression analysis at the end of the stressing period. For gene expression analysis during T39-induced resistance, relative expression values were calculated using NS uninoculated control plants at $24 \mathrm{~h}$ as the calibrator. The priming effect was calculated as the ratio between the expression level in inoculated ( $24 \mathrm{~h}$ post inoculation) leaves of T39-treated plants and the expression level in inoculated control plants, using a threshold of 1.5-fold to identify augmented expressions (58). For each sample, mean expression values and standard errors were calculated on three replicates, and two independent experiments were analyzed.
Primer design for heat-stress-related genes. Published sequences of three heat shock proteins (HSPs) (Table 1) were aligned against the Pinot Noir genome (57) release 3 (http://genomics. research.iasma.it): heat shock-induced gene (HSG) 4 (HSG4) (25), HSG19 (25), and the gene encoding the HSP 90 (HSP90.1a) (7). Sequences were aligned using ClustalW2 (www.ebi.ac.uk) and primer pairs were designed on the Pinot Noir sequences using the Primer 3 software v. 4.0 (http://primer3.sourceforge.net) and analyzed with the Oligo Analyzer v. 1.0.2 (www.bio.net/bionet/ $\mathrm{mm} /$ bio-soft/2001-September/023431.html).

Statistical analysis. Two independent experiments were carried out and variance of the data was analyzed using the Statistica 9 software (StatSoft, Tulsa, OK). An $F$ test was used to demonstrate nonsignificant treatment-experiment interactions $(P>0.05)$ and data from the repeated experiments were pooled. Values of $\Psi_{\text {leaf }}$ and T39 efficacy were $\log _{10}$ transformed, and foldchange values of gene expression analysis were transformed according to the equation $Y=\log _{10}(1+x)(9)$. A box and whisker plot was used to detect outliers. Normal distribution was evaluated with the $K-S$ test $(P>0.05)$. Data were validated for homogeneity of variance (Levene's test, $P>0.05$ ) and analysis of variance was carried out with a Fisher's test to detect significant differences $(P<0.05)$.

\section{RESULTS}

Soil moisture, $\Psi_{\text {leaf }}$, and leaf chlorophyll content during the stressing period. To monitor the effects of irrigation scheduling, soil water content was measured during abiotic stress exposure. The mean soil water content of NS plants and heat-stressed plants was $\approx 45 \%$ during the stressing period (Fig. 1A). The soil water content of drought-stressed plants was decreasing to $11 \%$ by the end of the stressing period, and that of HDS plants oscillated between 20 and $30 \%$, probably due to the small amount of water given to avoid wilting.

At the end of the stressing period (day 14), $\Psi_{\text {leaf }}$ in droughtstressed plants and in HDS plants was significantly lower than in NS plants (Fig. 1B). Values of $\Psi_{\text {leaf }}$ indicated the adaptation of grapevines to water stress $(30,31,40)$ at the end of the droughtstress and HDS condition and not at the end of heat-stress exposure.

TABLE 1. Primer sequences for quantitative real time reverse-transcription polymerase chain reaction (RT-qPCR) expression analysis of grapevine genes

\begin{tabular}{|c|c|c|c|c|c|c|}
\hline Name & Abbreviation & Accession number ${ }^{\mathrm{y}}$ & 'Pinot Noir' gene ${ }^{\mathrm{z}}$ & $\begin{array}{c}\text { RT-qPCR } \\
\text { primer name }\end{array}$ & RT-qPCR primer sequence & Reference \\
\hline \multirow[t]{2}{*}{ Pathogenesis-related protein 2} & \multirow[t]{2}{*}{$P R-2$} & \multirow[t]{2}{*}{ AJ 277900} & \multirow[t]{2}{*}{ twinscan.VV78X005385.7_1 } & PR-2_For & GTTATTTCAGAGAGTGGTTGGC & \\
\hline & & & & $P R-2 \_$Rev & AACATGGCAAACACGTAAGTCT & 36,39 \\
\hline \multirow[t]{2}{*}{ Lipooxygenase 9} & \multirow[t]{2}{*}{$L O X-9$} & \multirow[t]{2}{*}{ AY159556 } & \multirow[t]{2}{*}{ twinscan.VV78X044916.31_1 } & LOX-9_For & СССТTCTTGGCATCTCCСТTA & \\
\hline & & & & LOX-9_Rev & TGTTGTGTCCAGGGTCCATTC & 39,54 \\
\hline \multirow[t]{2}{*}{ Trichoderma-induced osmotin } & \multirow[t]{2}{*}{$O S M-1$} & \multirow[t]{2}{*}{ XM_002282928 } & \multirow[t]{2}{*}{ glimmer.VV78X132476.3_2 } & OSM-1_For & CGCTGCGCTAAAGACTACC & \\
\hline & & & & OSM-1_Rev & AAAAACCTTGAGTAATCTGTAGCA & 38 \\
\hline \multirow[t]{2}{*}{ Pathogenesis-related protein 4} & \multirow[t]{2}{*}{$P R-4$} & \multirow[t]{2}{*}{ CF74510 } & \multirow[t]{2}{*}{ glimmer.VV78X053121.6_1 } & PR-4_For & CAGGCAACGGTGAGAATAGT & \\
\hline & & & & PR-4_Rev & ACCACAGTCCACAAACTCGTA & 36,39 \\
\hline \multirow[t]{2}{*}{ Acidic endochitinase 3} & \multirow[t]{2}{*}{ CHIT3 } & \multirow[t]{2}{*}{ XM_003634041 } & \multirow[t]{2}{*}{ glimmer.VV78X036668.3_2 } & CHIT3_For & GTCCATTCCCAGATAAGTTCCT & \\
\hline & & & & CHIT3_Rev & CAGAAGGTTATTGGTGTTGCC & 38 \\
\hline \multirow{3}{*}{$\begin{array}{l}\text { Ethylene-responsive transcription } \\
\text { factor ERF003 }\end{array}$} & \multirow{3}{*}{$E R F$} & \multirow{3}{*}{ XM_002285337 } & \multirow{3}{*}{ glimmer.VV78X034923.15_2 } & & & \\
\hline & & & & $E R F_{-}$For & ACCAAACAATCCCTGCATGA & \\
\hline & & & & $E R F \_R e v$ & GGCTGCTGCACTGTCACC & 38 \\
\hline \multirow[t]{2}{*}{ Heat shock induced gene 4} & \multirow[t]{2}{*}{ HSG4 } & \multirow[t]{2}{*}{ GU169699 } & \multirow[t]{2}{*}{ glimmer.VV78X138978.6_1 } & HSG4_For & GAATGAAAGTGGCACCGAGT & \\
\hline & & & & HSG4_Rev & CCTCAGCCTTGGGAACAGTA & 25 \\
\hline \multirow[t]{2}{*}{ Heat shock induced gene 19} & \multirow[t]{2}{*}{ HSG19 } & \multirow[t]{2}{*}{ GU169701 } & \multirow[t]{2}{*}{ glimmer.VV78X000784.5_3 } & HSG19_For & TATGAGGAAGTTTGCGTTGC & \\
\hline & & & & HSG19_Rev & TCAATGGTCTTGGGCTTCTT & 25 \\
\hline \multirow[t]{2}{*}{ Heat shock protein 90} & \multirow[t]{2}{*}{$V v H S P 90.1 a$} & \multirow[t]{2}{*}{ XP_002274022 } & glimmer.VV78X151268.17_1 & HSP90_For & CCTCCTGACTTCTGGGTTCA & \\
\hline & & & & HSP90_Rev & ATGTCAGCATCCTCCTCACC & 7 \\
\hline Actin & Act & TC81781 & glimmer.VV78X114914.6_2 & Act_For & ATTCCTCACCATCATCAGCA & \\
\hline & & & & Act_Rev & GACССССТССТАСТАAАACT & 45 \\
\hline
\end{tabular}

y Accession numbers refer to the National Center for Biotechnology Information (NCBI) GenBank (www.ncbi.nlm.nih.gov).

${ }^{\mathrm{z}}$ The corresponding Pinot Noir genes used for primer design were identified by a nucleotide BLAST search against the Vitis vinifera 'Pinot Noir' predicted genes (57) of Release 3 (http://genomics.research.iasma.it/). 
No signs of wilting or of reduced chlorophyll content were visible in plants in any of the stressing conditions: chlorophyll content did not differ significantly between the four growth conditions at day $1\left(279 \pm 2 \mathrm{mg} \mathrm{m}^{-2}\right)$ and at day $11\left(301 \pm 4 \mathrm{mg} \mathrm{m}^{-2}\right)$.

Severity of downy mildew and efficacy of T39-induced resistance in grapevines exposed to abiotic stresses. Values of downy mildew severity and T39 efficacy revealed nonsignificant treatment-experiment interactions ( $F$ test, $P>0.05$ ), and the results of two independent experiments were pooled. Downy mildew severity of control plants treated with distilled water was comparable in NS and abiotic stressed plants (Supplemental Table 1 ), indicating that the increase of temperature or reduction of plant irrigation did not affect pathogen infection and symptom development. As previously reported $(37,39)$, foliar application of T39 significantly reduced downy mildew severity compared with control plants under NS condition. T39 treatment also reduced disease severity in plants exposed to single abiotic stress (drought or heat) but not in HDS plants. In particular, the efficacy of T39-
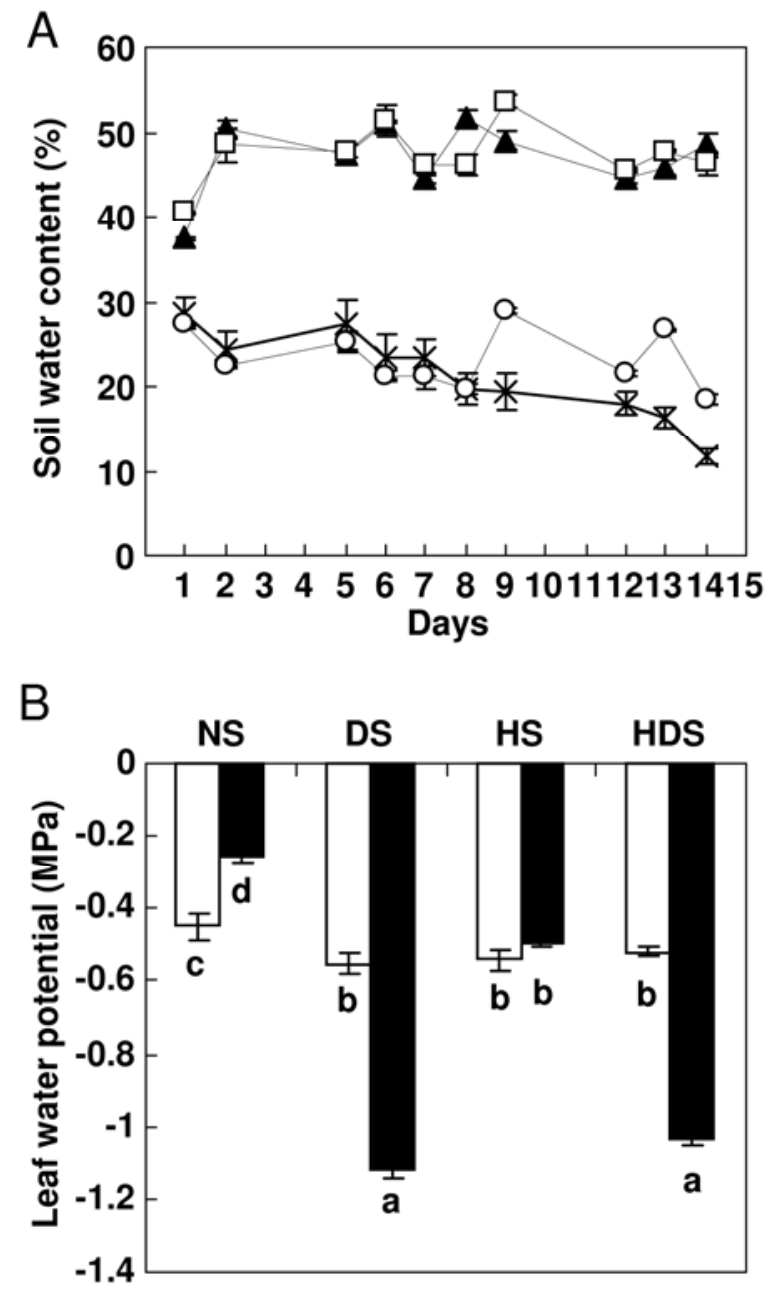

Fig. 1. A, Soil water content (percentage of volume) was measured in pots of 'Pinot Noir' grapevine plants subjected to unstressed conditions $(\mathbf{\Delta})$, drought stress $(\times)$, heat stress $(\square)$, and heat + drought stress (O) for 14 days. Each point represents the mean and standard error of 36 replicates (plants) pooled from two independent repetitions of the experiment. B, Leaf water potential ( $\left.\Psi_{\text {leaf }}\right)$ was measured in grapevine plants subjected to unstressed conditions (NS), drought stress (DS), heat stress (HS), and heat + drought stress (HDS) for 14 days. Three leaves per plant were analyzed at the beginning (white, day 1 ) and at the end (black, day 14) of the stressing period. An $F$ test revealed nonsignificant treatment-experiment interactions $(P>0.05)$ and data from two repetitions of the experiment were pooled. Values are means of eight plants pooled from two independent repetitions of the experiment. Different letters indicate significant differences according to a Fisher's test $(P<0.05)$ on $\log _{10}$-transformed values. induced resistance in NS plants was $53 \pm 7 \%$ (Fig. 2); the extent of downy mildew sporulation on NS T39-treated plants was approximately half that on NS control plants. The efficacy of T39induced resistance in drought-stressed and heat-stressed plants was comparable with NS plants, indicating that the increase in environmental temperature or reduction in plant irrigation did not affect interaction with the beneficial microorganism and the level of induced resistance in grapevine. Interestingly, the efficacy of T39-induced resistance to downy mildew was significantly lower in HDS plants (19 $\pm 1 \%$ of T39 efficacy) than in NS plants, indicating the negative effect of exposure to combined abiotic stresses.

Modulation of heat-stress markers and defense-related genes in grapevines exposed to abiotic stresses. Gene expression analysis was carried out on leaves collected on the last day of the stressing period, immediately before $P$. viticola inoculation (Table 2; Fig. 3). NS and HDS plants of both control and T39treated plants were analyzed. The gene expression levels of HSG4, HSG 19, and HSP90.1a were induced in HDS control and HDS T39-treated plants, whereas they remained at constitutive levels in NS control and NS T39-treated plants (Table 2), demonstrating that $35^{\circ} \mathrm{C}$ caused heat stress for plants.

The defense-related genes were modulated in NS and HDS plants before pathogen inoculation (Fig. 3). A sevenfold repression of the gene encoding the pathogenesis-related (PR) protein 2 $(P R-2)$ was observed in HDS control plants compared with NS control plants (Fig. 3A). Moreover, the level of $P R-2$ expression was 1.9-fold lower in HDS T39-treated compared with NS control plants.

A significant repression (2.9-fold) of lipoxygenase 9 (LOX-9) was observed in HDS control plants compared with NS control plants (Fig. 3B). LOX-9 is a marker of JA signaling $(23,39)$ and its expression level in HDS T39-treated plants was similar to NS control plants. However, LOX-9 was not induced by T39 treatment in either HDS or NS plants.

The Trichoderma-induced osmotin $1(O S M-1)$ was repressed (2.4-fold) in HDS control plants compared with NS control plants (Fig. 3C). Grapevine OSM-1 is a marker of T39-induced resistance (38) and it was induced by T39 treatment in both

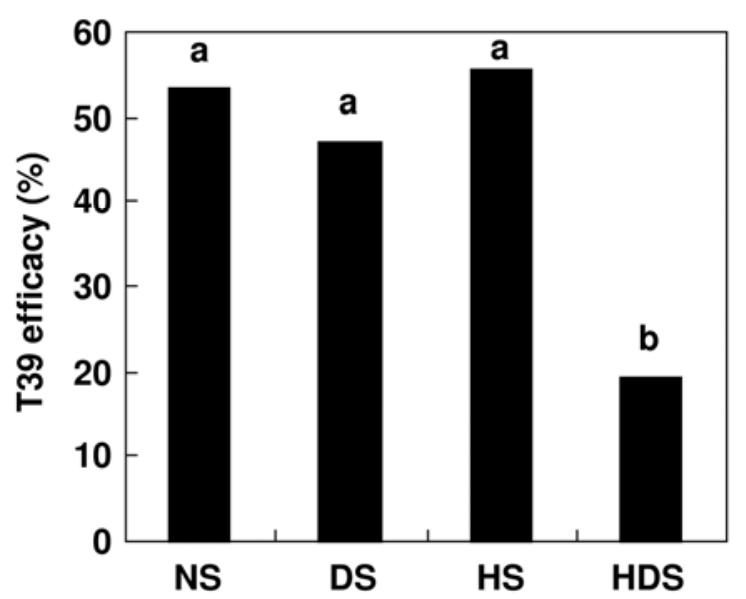

Fig. 2. Efficacy of Trichoderma harzianum T39 (T39) against downy mildew in grapevine plants exposed to unstressed (NS), drought-stressed (DS), heatstressed (HS), and heat + drought stressed (HDS) conditions. Downy mildew severity was assessed on all leaves of each plant as percentage of abaxial leaf area covered by sporulation of downy mildew. Efficacy of T39 was calculated for each growth condition according to the equation efficacy $=$ (severity of control plants - severity of T39-treated plants)/severity of control plants $\times$ 100. An $F$ test revealed nonsignificant treatment-experiment interactions $(P>$ $0.05)$ and data from two repetitions of the experiment were pooled. Each bar represents the mean of 12 replicates (plants) pooled from two independent repetitions of the experiment. Different letters indicate significant differences among treatments and growth conditions, according to Fisher's test $(P<0.05)$. 
NS (3.8-fold) and HDS (2.0-fold) plants compared with NS control plants. Interestingly, the expression level of $O S M-1$ in T39-treated plants was significantly lower in the HDS than in the NS plants.

No significant modulation of the gene encoding the $P R-4$ was observed in HDS control plants compared with NS control plants (Fig. 3D). $P R-4$ is a marker of JA signaling known to be involved in T39-induced resistance (39) and it was significantly induced by T39 treatment in both NS and HDS plants. Likewise, no changes in acid endochitinase 3 (CHIT3) gene expression were observed in HDS control plants compared with NS control plants (Fig. 3E). The CHIT3 gene is induced by T39 in grapevine (38) and, in our experiments, it was induced by T39 treatment in both NS and HDS plants. The level of CHIT3 expression did not vary between HDS plants and NS plants, and it was twofold higher in T39treated than in control samples. The ET-responsive transcription factor $(E R F)$ was not modulated in T39-treated and control plants in either NS or HDS conditions (Fig. 3F), in agreement with the finding that this gene is modulated only after pathogen inoculation in T39-treated grapevines (38).

Modulation of defense-related genes during $T$. harzianum T39-induced resistance under stress conditions. Expression of the above-mentioned defense-related genes was analyzed in leaves collected at $24 \mathrm{~h}$ after $P$. viticola inoculation (Fig. 4). Because the plants were kept under the same environmental conditions during inoculation, heat and drought stress had ceased in the leaves sampled $24 \mathrm{~h}$ after $P$. viticola inoculation. $P R-2$ was significantly induced by $P$. viticola in NS control plants but not in HDS control plants (Fig. 4A). The highest level of $P R-2$ expression was observed in inoculated NS T39-treated plants, with a priming effect of 1.9-fold compared with inoculated NS control plants. In T39treated plants, the expression level of $P R-2$ after inoculation was lower in the HDS than in the NS plants.

$L O X-9$ is usually induced by $P$. viticola inoculation $(23,39)$ and, in our experiments, it was significantly induced only in NS T39treated plants after inoculation (Fig. 4B). LOX-9 was not significantly affected by the abiotic stresses in uninoculated plants, and its expression after inoculation was lower in HDS T39-treated than in NS T39-treated plants.

OSM-1 was not modulated in uninoculated control plants and induction caused by T39 was not significant in either NS or HDS plants at $24 \mathrm{~h}$ (Fig. 4C). The highest level of $O S M-1$ expression was observed in NS T39-treated plants after $P$. viticola inoculation, with a significant priming effect of 1.8-fold compared with inoculated NS control plants. In $P$. viticola-inoculated samples, the expression level of $O S M-1$ was lower in HDS T39-treated than in NS T39-treated plants.

$P R-4$ was not significantly modulated in uninoculated plants at $24 \mathrm{~h}$ and was induced by $P$. viticola inoculation with similar expression levels in all tested conditions (Fig. 4D). CHIT3 was not significantly modulated in uninoculated plants in any of the tested conditions and was induced by $P$. viticola in NS control plants (Fig. 4E). In P. viticola-inoculated samples, the expression level of CHIT3 was higher in NS T39-treated than in NS control plants, with a significant priming effect of 1.8-fold. Under HDS conditions, CHIT3 was induced by $P$. viticola in both T39-treated and control plants but no significant priming effect was observed compared with HDS inoculated control plants. ERF was induced by $P$. viticola inoculation in T39-treated but not in control plants under NS conditions (Fig. 4F), in agreement with Perazzolli et al.
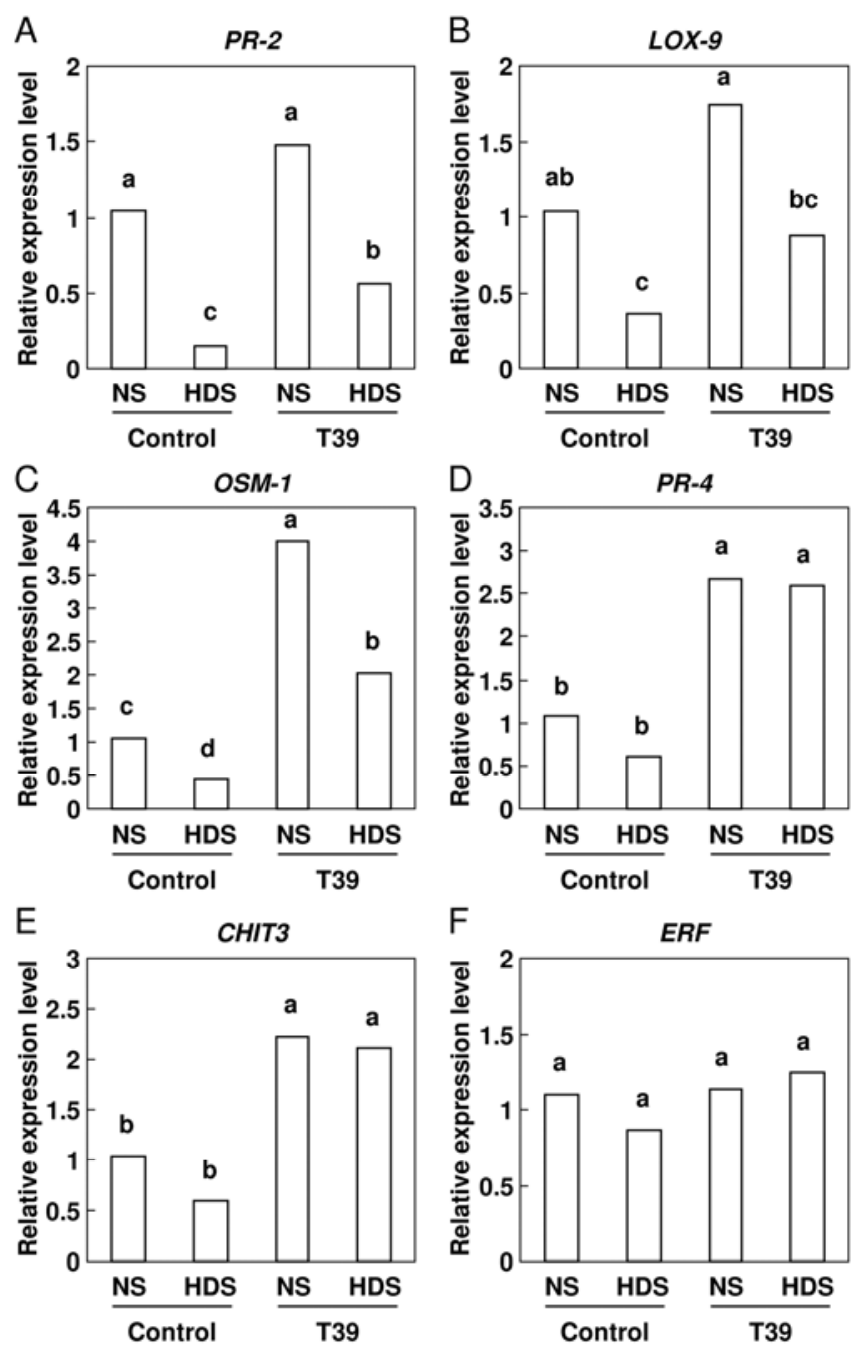

Fig. 3. Gene expression analysis of genes encoding $\mathbf{A}$, pathogenesis-related protein 2 (PR-2); B, lipoxygenease 9 (LOX-9); C, Trichoderma-induced osmotin $1(O S M-1)$; D, $P R-4 ; \mathbf{E}$, acid endochitinase 3 (CHIT3); and $\mathbf{F}$, ethylene response factor $(E R F)$ in 'Pinot Noir' grapevine plants. Analysis was performed on unstressed (NS) and heat + drought-stressed (HDS) grapevine plants treated with distilled water (Control) or with Trichoderma harzianum T39 (T39). Relative expression levels (fold changes) were calculated using Actin as the constitutive gene for normalization and data were calibrated on uninoculated NS control plants at $0 \mathrm{~h}$. An $F$ test revealed nonsignificant treatmentexperiment interactions $(P>0.05)$ and data from two repetitions of the experiment were pooled. Mean levels of relative expression were calculated from six replicates (plants) per treatment pooled from two independent repetitions of the experiment. For each gene, different letters indicate significant differences according to Fisher's test $(P<0.05)$ on fold change values transformed according to the equation $Y=\log _{10}(1+x)(9)$.

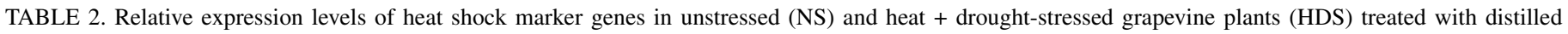
water (control) or with Trichoderma harzianum T39 (T39) ${ }^{\mathrm{z}}$

\begin{tabular}{|c|c|c|c|c|c|}
\hline Gene name & Abbreviation & NS control & HDS control & NS T39-treated & HDS T39-treated \\
\hline Heat shock-induced gene 4 & HSG4 & $1.2 \pm 0.7 \mathrm{c}$ & $80.4 \pm 1.5 b$ & $0.7 \pm 0.1 \mathrm{c}$ & $63.8 \pm 2.7 \mathrm{a}$ \\
\hline Heat shock-induced gene 19 & HSG19 & $1.1 \pm 0.5 \mathrm{~b}$ & $25.7 \pm 1.4 \mathrm{a}$ & $0.7 \pm 0.1 \mathrm{~b}$ & $21.0 \pm 3.5 \mathrm{a}$ \\
\hline Heat shock protein $90.1 \mathrm{a}$ & HSP90.1a & $2.3 \pm 1.1 \mathrm{~b}$ & $520.7 \pm 25.4 \mathrm{a}$ & $2.5 \pm 0.5 b$ & $433.9 \pm 106.1 \mathrm{a}$ \\
\hline
\end{tabular}

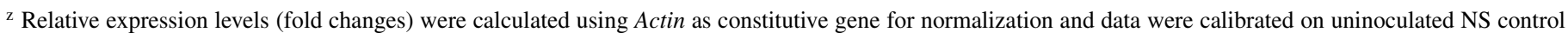
plants at $0 \mathrm{~h}$. Mean levels of relative expression and standard errors were calculated from six replicates (plants) per treatment pooled from two independent

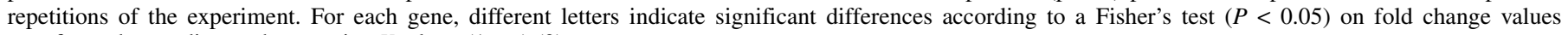
transformed according to the equation $Y=\log _{10}(1+x)(9)$. 
(38). Moreover, induction of ERF was also observed in both inoculated and uninoculated HDS plants.

\section{DISCUSSION}

Trichoderma spp. have been recognized as biocontrol agents for several pathogens through different mechanisms of action (50). The T39 strain reduces downy mildew severity in grapevine by inducing systemic resistance, without any direct toxic effect on $P$. viticola sporangia (37). T39-induced resistance is mediated by JA and ET signaling pathways (26) and does not entail energy costs for grapevine plants, suggesting minimal deleterious effects on grape production and quality (39). The mechanisms of T39induced resistance are based on a complex reprogramming of the
A
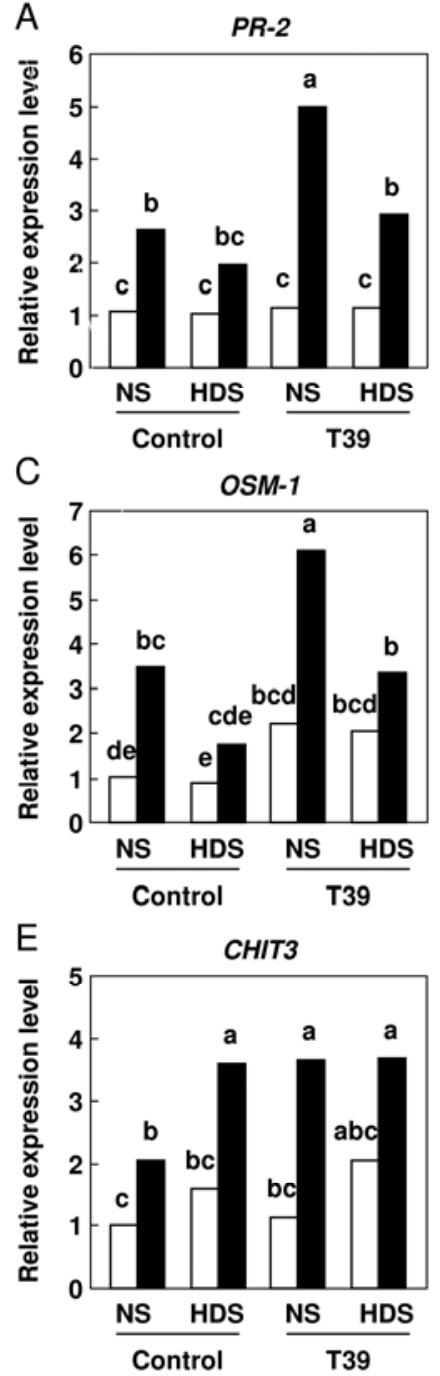

B
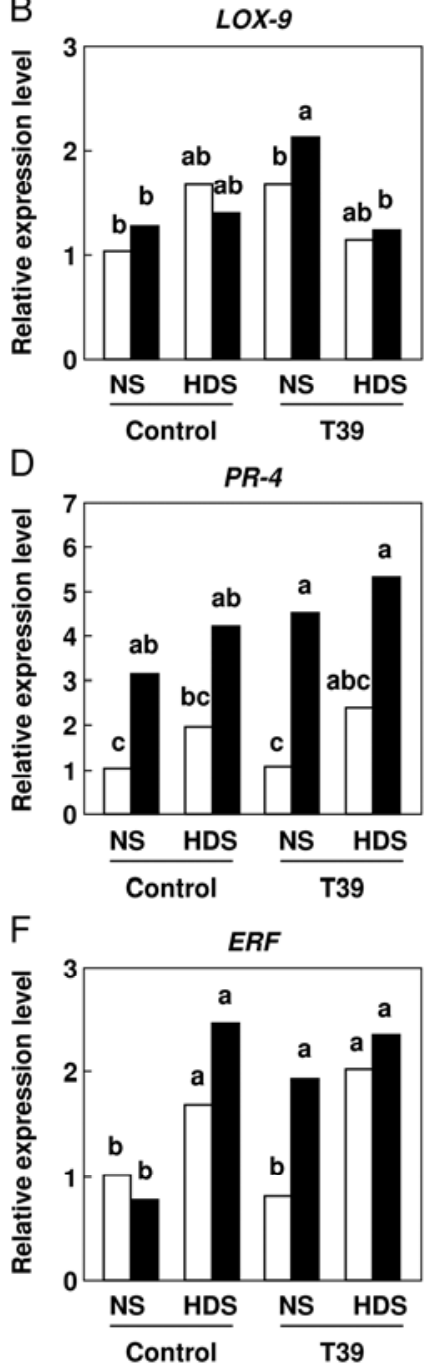

Fig. 4. Gene expression analysis of genes encoding $\mathbf{A}$, pathogenesis-related protein $2(P R-2) ; \mathbf{B}$, lipoxygenease 9 (LOX-9); C, Trichoderma-induced osmotin 1 (OSM-1); D, PR-4; E, acid endochitinase 3 (CHIT3); and F, ethylene response factor $(E R F)$ in 'Pinot Noir' grapevine plants either uninoculated (white) or inoculated with Plasmopara viticola (black) at $24 \mathrm{~h}$. Analysis was performed on unstressed (NS) and heat + drought-stressed grapevine plants (HDS) treated with distilled water (Control) or with Trichoderma harzianum T39 (T39). Relative expression levels (fold changes) were calculated using Actin as the constitutive gene for normalization and data were calibrated on uninoculated NS control plants at $24 \mathrm{~h}$. An $F$ test revealed nonsignificant treatment-experiment interactions $(P>0.05)$ and data from two repetitions of the experiment were pooled. Mean levels of relative expression were calculated from six replicates (plants) per treatment pooled from two independent repetitions of the experiment. For each gene, different letters indicate significant differences according to Fisher's test $(P<0.05)$ on fold change values transformed according to the equation $Y=\log _{10}(1+x)(9)$. leaf transcriptome (38) and proteome (34), with early activation of plant defense processes (e.g., accumulation of callose and ROS) after downy mildew inoculation (34). Resistance induced by beneficial microorganisms is usually characterized by priming activation $(6,12,58)$ and broad-spectrum effectiveness to various types of pathogens (56). Therefore, microbial elicitors of induced resistance seem to be promising biocontrol methods for disease management of crops $(55,62)$. However, the potential of induced resistance has yet to be fully realized, mainly due to its only partial control of the disease and its inconsistency under field conditions (60-62). Induced resistance is a plant-mediated mechanism, and its expression is likely to be influenced by a number of factors, including environment, genotype, and crop nutrition $(60,61)$. Activation of defense processes has been found to be negatively affected by limiting nitrogen supply $(15,60)$, and it could also be affected by other abiotic stresses which alter the physiological status of the plant. Concerns about the impact of abiotic stresses on agriculture have been raised in the last decade, especially in light of the predicted effects of climate changes (28). High temperatures and drought associated with heat waves may occur with increased frequency as a result of climate change (24), threatening crop production and influencing interactions with both pathogenic $(17,35,63)$ and beneficial $(11)$ microorganisms. Whereas the effects of abiotic stresses on plant resistance to pathogens have been extensively studied (5), their effects on resistance mechanisms activated by resistance inducers has received little attention (8). Moreover, the effects of increased temperature on beneficial plant-associated microorganisms have been found to be variable (11), highlighting the complexity of this system.

In this study, we investigated the effect of exposing grapevines to a short period of heat, drought, or both on plant resistance induced by treatments with the beneficial microorganism T39. To the best of our knowledge, this study is the first to analyze the effect of abiotic stresses on induced resistance mechanisms in grapevine. We found that exposure to HDS significantly reduced the efficacy of T39-induced resistance to downy mildew. However, the efficacy of T39-induced resistance was not affected by a single abiotic stress (heat or drought). Although no symptoms of abiotic stress were visible, $\Psi_{\text {leaf }}$ values and expression profiles of heat-stress-related genes confirmed that plants reacted to water deficit and to heat. Decrease of $\Psi_{\text {leaf }}$ has been previously shown in drought-stressed grapevines $(30,31,40,47)$ and has been associated with accumulation of $\mathrm{ABA}$ and reduction of stomatal conductance $(30,47)$, confirming activation of drought-stress responses in grapevines at the end of the stressing period. Likewise, modulation of genes encoding heat stress-related proteins $(7,25$, 59) indicated that plants reacted to heat, and the combination of abiotic stresses was associated with decreased efficacy of T39 against downy mildew. At the end of the stressing period, the expressions of $P R-2, L O X-9$, and $O S M-1$ were lower in HDS control plants than in NS control plants, demonstrating that abiotic stress negatively affects the basal expression of some defense-related genes. Negative effects of abiotic stresses on gene expression were also found during T39-induced resistance. The expression levels of $P R-2, L O X-9$, and $O S M-1$ were lower in HDS T39-treated plants than in NS T39-treated plants before inoculation, indicating attenuated reaction to the beneficial microorganism in stressed plants. In HDS T39-treated plants, no priming of PR-2, OSM-1, and CHIT3 was observed and expression of $P R-2, L O X-9$, and $O S M-1$ after $P$. viticola inoculation was attenuated, in agreement with the weaker efficacy of T39-induced resistance. However, the expression levels of PR-4, CHIT3, and $E R F$ after inoculation were comparable in HDS and NS plants, indicating that abiotic stresses did not cause global inhibition of transcription for all genes related to T39-induced resistance.

The abiotic stress response in plants is mainly controlled by ABA (14), and this hormone is also involved in regulating defense 
responses to biotic stresses together with the SA, JA, and ET signaling pathways (48). Crosstalk of the signaling pathways that tune plant reactions to biotic and abiotic stresses is extremely complex, and ABA signaling plays a crucial role in modulating defense reactions under exposure to multiple stresses $(4,5,48,52)$. Recent evidence has highlighted the fact that plants respond differently to multiple stresses than to individual stresses (5), confirming that more information is needed on the effect of abiotic stress on biocontrol tools based on induced resistance (60). For example, it has been shown that salt stress has a positive effect on $\beta$-aminobutyric acid (BABA)-induced resistance (8). However, ABA signaling mediates both BABA-induced resistance (53) and tolerance to salt stress $(1,16)$, suggesting synergic activation of ABA signaling in response to abiotic stress and BABA treatment. Our results show that abiotic stresses antagonize T39-induced resistance to downy mildew in grapevine. T39-induced resistance is mediated by JA and ET signaling pathways $(26,39)$ and was not efficiently activated in ABA-impaired Arabidopsis mutants (26), indicating crosstalk in hormonal signaling during T39-induced resistance. ABA signaling antagonizes the JA- and ET-mediated defense response $(3,5)$, in agreement with the negative effects of abiotic stresses on T39-induced resistance. Therefore, the effects of abiotic stresses on induced resistance are highly dependent on the resistance inducer and the signaling molecules involved, demonstrating the need for specific characterizations for each inducer and each pathosystem.

Although resistance inducers represent potential biocontrol alternatives to chemical fungicides given their low impact on the environment, more knowledge about the role of the physiological status of the plant is required in order to maximize their efficacy under field conditions (62). The evidence reported here indicated that exposure to abiotic stresses could be one of the possible explanations for the inconsistencies and weaknesses of resistance inducers under field conditions, where plants are frequently exposed to various abiotic stresses. This information seems to be particularly important given future climate changes, because warmer and drier summers are predicted in several regions (24). In order to further analyze the effect of resistance inducers under field conditions, the possible exposure of plants to abiotic stresses need to be taken into account in future experimental trials. For this purpose, expression analysis of defense-related genes and abiotic stress markers in vineyards could be helpful to evaluate plant status and to predict the ability of the plant to react to resistance inducers. Accurate studies investigating the thresholds of abiotic stresses (alone or in combination) which affect crop responses to beneficial and pathogenic microorganisms need to be carried out, and the expression analysis of specific defense-related genes will contribute to the quantitative analysis of the impact of abiotic conditions on induced resistance under varying environmental conditions.

\section{ACKNOWLEDGMENTS}

B. Roatti and M. Perazzolli contributed equally to this work. This research was supported by the EnviroChange Project funded by the Autonomous Province of Trento and the EU project CO-FREE (theme KBBE.2011.1.2-06, grant agreement number 289497). We thank O. Giovannini for technical support with the greenhouse experiments and R. Zorer for providing us with the Scholander-type pressure chamber.

\section{LITERATURE CITED}

1. Achard, P., Cheng, H., De Grauwe, L., Decat, J., Schoutteten, H., Moritz, T., Van Der Straeten, D., Peng, J., and Harberd, N. P. 2006. Integration of plant responses to environmentally activated phytohormonal signals. Science 311:91-94.

2. Adie, B. A. T., Pérez-Pérez, J., Pérez-Pérez, M. M., Godoy, M., SánchezSerrano, J.-J., Schmelz, E. A., and Solano, R. 2007. ABA is an essential signal for plant resistance to pathogens affecting JA biosynthesis and the activation of defenses in Arabidopsis. Plant Cell 19:1665-1681.
3. Anderson, J. P., Badruzsaufari, E., Schenk, P. M., Manners, J. M., Desmond, O. J., Ehlert, C., Maclean, D. J., Ebert, P. R., and Kazan, K. 2004. Antagonistic interaction between abscisic acid and jasmonateethylene signaling pathways modulates defense gene expression and disease resistance in Arabidopsis. Plant Cell 16:3460-3479.

4. Asselbergh, B., De Vleesschauwer, D., and Höfte, M. 2008. Global switches and fine-tuning-ABA modulates plant pathogen defense. Mol. Plant-Microbe Interact. 21:709-719.

5. Atkinson, N. J., and Urwin, P. E. 2012. The interaction of plant biotic and abiotic stresses: From genes to the field. J. Exp. Bot. 63:3523-3543.

6. Banani, H., Roatti, B., Ezzahi, B., Giovannini, O., Gessler, C., Pertot, I., and Perazzolli, M. Characterization of resistance mechanisms activated by Trichoderma harzianum T39 and benzothiadiazole to downy mildew in different grapevine cultivars. Plant Pathol. DOI: 1111/ppa.12089

7. Banilas, G., Korkas, E., Englezos, V., Nisiotou, A. A., and Hatzopoulos, P. 2012. Genome-wide analysis of the heat shock protein 90 gene family in grapevine (Vitis vinifera L.). Aust. J. Grape Wine Res. 18:29-38.

8. Baysal, Ö., Gürsoy, Y. Z., Örnek, H., Çetinel, B., and Teixeira da Silva, J. A. 2007. Enhanced systemic resistance to bacterial speck disease caused by Pseudomonas syringae pv. tomato by DL- $\beta$-aminobutyric acid under salt stress. Physiol. Plant. 129:493-506.

9. Casagrande, K., Falginella, L., Castellarin, S., Testolin, R., and Di Gaspero, G. 2011. Defence responses in Rpv3-dependent resistance to grapevine downy mildew. Planta 234:1097-1109.

10. Ciais, P., Reichstein, M., Viovy, N., Granier, A., Ogee, J., Allard, V., Aubinet, M., Buchmann, N., Bernhofer, C., Carrara, A., Chevallier, F., De Noblet, N., Friend, A. D., Friedlingstein, P., Grunwald, T., Heinesch, B., Keronen, P., Knohl, A., Krinner, G., Loustau, D., Manca, G., Matteucci, G., Miglietta, F., Ourcival, J. M., Papale, D., Pilegaard, K., Rambal, S., Seufert, G., Soussana, J. F., Sanz, M. J., Schulze, E. D., Vesala, T., and Valentini, R. 2005. Europe-wide reduction in primary productivity caused by the heat and drought in 2003. Nature 437:529-533.

11. Compant, S., Van Der Heijden, M. G. A., and Sessitsch, A. 2010. Climate change effects on beneficial plant-microorganism interactions. FEMS Microbiol. Ecol. 73:197-214.

12. Conrath, U., Beckers, G. J. M., Flors, V., García-Agustín, P., Jakab, G., Mauch, F., Newman, M.-A., Pieterse, C. M. J., Poinssot, B., Pozo, M. J., Pugin, A., Schaffrath, U., Ton, J., Wendehenne, D., Zimmerli, L., and Mauch-Mani, B. 2006. Priming: Getting ready for battle. Mol. PlantMicrobe Interact. 19:1062-1071.

13. Corio-Costet, M. F., Dufour, M. C., Cigna, J., Abadie, P., and Chen, W. J. 2011. Diversity and fitness of Plasmopara viticola isolates resistant to QoI fungicides. Eur. J. Plant Pathol. 129:315-329.

14. Cramer, G., Urano, K., Delrot, S., Pezzotti, M., and Shinozaki, K. 2011. Effects of abiotic stress on plants: A systems biology perspective. BMC Plant Biol. 11:163.

15. Dietrich, R., Ploß, K., and Heil, M. 2004. Constitutive and induced resistance to pathogens in Arabidopsis thaliana depends on nitrogen supply. Plant Cell Environ. 27:896-906.

16. Duan, L., Dietrich, D., Ng, C. H., Chan, P. M. Y., Bhalerao, R., Bennett, M. J., and Dinneny, J. R. 2013. Endodermal ABA signaling promotes lateral root quiescence during salt stress in Arabidopsis seedlings. Plant Cell 25:324-341.

17. Eastburn, D. M., McElrone, A. J., and Bilgin, D. D. 2011. Influence of atmospheric and climatic change on plant-pathogen interactions. Plant Pathol. 60:54-69.

18. European and Mediterranean Plant Protection Organization (EPPO) 2001. Guidelines for the efficacy evaluation of fungicides: Plasmopara viticola. EPPO Bull. 31:313-317

19. Flexas, J., Barón, M., Bota, J., Ducruet, J. M., Gallé, A., Galmés, J., Jiménez, M., Pou, A., Ribas-Carbó, M., Sajnani, C., Tomàs, M., and Medrano, H. 2009. Photosynthesis limitations during water stress acclimation and recovery in the drought-adapted Vitis hybrid Richter-110 (V. berlandieri $\times$ V. rupestris). J. Exp. Bot. 60:2361-2377.

20. Flors, V., Ton, J., Van Doorn, R., Jakab, G., García-Agustín, P., and Mauch-Mani, B. 2008. Interplay between JA, SA and ABA signalling during basal and induced resistance against Pseudomonas syringae and Alternaria brassicicola. Plant J. 54:81-92.

21. Fujita, M., Fujita, Y., Noutoshi, Y., Takahashi, F., Narusaka, Y., YamaguchiShinozaki, K., and Shinozaki, K. 2006. Crosstalk between abiotic and biotic stress responses: A current view from the points of convergence in the stress signaling networks. Curr. Opin. Plant Biol. 9:436-442.

22. Gessler, C., Pertot, I., and Perazzolli, M. 2011. Plasmopara viticola: A review of knowledge on downy mildew of grapevine and effective disease management. Phytopathol. Mediterr. 50:3-44.

23. Hamiduzzaman, M. M., Jakab, G., Barnavon, L., Neuhaus, J. M., and Mauch-Mani, B. 2005. $\beta$-Aminobutyric acid-induced resistance against downy mildew in grapevine acts through the potentiation of callose formation and jasmonic acid signaling. Mol. Plant-Microbe Interact. 18:819-829. 
24. Intergovernmental Panel on Climate Change (IPCC). 2007. Climate change. Synthesis report. Summary for policy markers. http://www.ipcc.ch

25. Kobayashi, M., Katoh, H., Takayanagi, T., and Suzuki, S. 2010. Characterization of thermotolerance-related genes in grapevine (Vitis vinifera). J. Plant Physiol. 167:812-819.

26. Korolev, N., Rav David, D., and Elad, Y. 2008. The role of phytohormones in basal resistance and Trichoderma-induced systemic resistance to Botrytis cinerea in Arabidopsis thaliana. BioControl 53:667-683.

27. Liu, G. T., Wang, J. F., Cramer, G., Dai, Z. W., Duan, W., Xu, H. G., Wu, B. H., Fan, P. G., Wang, L. J., and Li, S. H. 2012. Transcriptomic analysis of grape (Vitis vinifera L.) leaves during and after recovery from heat stress. BMC Plant Biol. 12:174.

28. Lobell, D. B., Schlenker, W., and Costa-Roberts, J. 2011. Climate trends and global crop production since 1980. Science 333:616-620.

29. Longa, C. M. O., Savazzini, F., Tosi, S., Elad, Y., and Pertot, I. 2009. Evaluating the survival and environmental fate of the biocontrol agent Trichoderma atroviride SC1 in vineyards in northern Italy. J. Appl. Microbiol. 106:1549-1557.

30. Lovisolo, C., Hartung, W., and Schubert, A. 2002. Whole-plant hydraulic conductance and root-to-shoot flow of abscisic acid are independently affected by water stress in grapevines. Funct. Plant Biol. 29:1349-1356.

31. Lovisolo, C., Perrone, I., Hartung, W., and Schubert, A. 2008. An abscisic acid-related reduced transpiration promotes gradual embolism repair when grapevines are rehydrated after drought. New Phytol. 180:642-651.

32. Malacarne, G., Vrhovsek, U., Zulini, L., Cestaro, A., Stefanini, M., Mattivi, F., Delledonne, M., Velasco, R., and Moser, C. 2011. Resistance to Plasmopara viticola in a grapevine segregating population is associated with stilbenoid accumulation and with specific host transcriptional responses. BMC Plant Biol. 11:114.

33. Mauch-Mani, B., and Mauch, F. 2005. The role of abscisic acid in plantpathogen interactions. Curr. Opin. Plant Biol. 8:409-414.

34. Palmieri, M. C., Perazzolli, M., Matafora, V., Moretto, M., Bachi, A., and Pertot, I. 2012. Proteomic analysis of grapevine resistance induced by Trichoderma harzianum T39 reveals specific defence pathways activated against downy mildew. J. Exp. Bot. 63:6237-6251.

35. Pautasso, M., Döring, T., Garbelotto, M., Pellis, L., and Jeger, M. 2012. Impacts of climate change on plant diseases-opinions and trends. Eur. J. Plant Pathol. 133:295-313.

36. Perazzolli, M., Bampi, F., Faccin, S., Moser, M., De Luca, F., Ciccotti, A. M., Velasco, R., Gessler, C., Pertot, I., and Moser, C. 2010. Armillaria mellea induces a set of defense genes in grapevine roots and one of them codifies a protein with antifungal activity. Mol. Plant-Microbe Interact. 23:485-496.

37. Perazzolli, M., Dagostin, S., Ferrari, A., Elad, Y., and Pertot, I. 2008. Induction of systemic resistance against Plasmopara viticola in grapevine by Trichoderma harzianum $\mathrm{T} 39$ and benzothiadiazole. Biol. Control 47:228-234.

38. Perazzolli, M., Moretto, M., Fontana, P., Ferrarini, A., Velasco, R., Moser, C., Delledonne, M., and Pertot, I. 2012. Downy mildew resistance induced by Trichoderma harzianum T39 in susceptible grapevines partially mimics transcriptional changes of resistant genotypes. BMC Genomics 13:660.

39. Perazzolli, M., Roatti, B., Bozza, E., and Pertot, I. 2011. Trichoderma harzianum $\mathrm{T} 39$ induces resistance against downy mildew by priming for defense without costs for grapevine. Biol. Control 58:74-82.

40. Perrone, I., Pagliarani, C., Lovisolo, C., Chitarra, W., Roman, F., and Schubert, A. 2012. Recovery from water stress affects grape leaf petiole transcriptome. Planta 235:1383-1396.

41. Pfaffl, M. W. 2001. A new mathematical model for relative quantification in real-time RT-PCR. Nucleic Acids Res. 29:e45.

42. Pieterse, C. M. J., Leon-Reyes, A., Van der Ent, S., and Van Wees, S. C. M. 2009. Networking by small-molecule hormones in plant immunity. Nat. Chem. Biol. 5:308-316.

43. Pieterse, C. M. J., van der Does, D., Zamioudis, C., Leon-Reyes, A., and van Wees, S. C. M. 2012. Hormonal modulation of plant immunity. Annu. Rev. Cell Dev. Biol. 28:489-521.

44. Pieterse, C. M. J., Van Pelt, J. A., Ton, J., Parchmann, S., Mueller, M. J., Buchala, A. J., Métraux, J. P., and Van Loon, L. C. 2000. Rhizobacteriamediated induced systemic resistance (ISR) in Arabidopsis requires sensitivity to jasmonate and ethylene but is not accompanied by an increase in their production. Physiol. Mol. Plant Pathol. 57:123-134.

45. Polesani, M., Bortesi, L., Ferrarini, A., Zamboni, A., Fasoli, M., Zadra, C., Lovato, A., Pezzotti, M., Delledonne, M., and Polverari, A. 2010.
General and species-specific transcriptional responses to downy mildew infection in a susceptible (Vitis vinifera) and a resistant (V. riparia) grapevine species. BMC Genomics 11:117.

46. Poni, S., Bernizzoni, F., Civardi, S., Gatti, M., Porro, D., and Camin, F 2009. Performance and water-use efficiency (single-leaf vs. wholecanopy) of well-watered and half-stressed split-root Lambrusco grapevines grown in Po Valley (Italy). Agric. Ecosyst. Environ. 129:97-106.

47. Pou, A., Medrano, H., Flexas, J., and Tyerman, S. D. 2013. A putative role for TIP and PIP aquaporins in dynamics of leaf hydraulic and stomatal conductances in grapevine under water stress and re-watering. Plant Cell Environ. 36:828-843.

48. Robert-Seilaniantz, A., Grant, M., and Jones, J. D. G. 2011. Hormone crosstalk in plant disease and defense: More than just jasmonate-salicylate antagonism. Annu. Rev. Phytopathol. 49:317-343.

49. Ruijter, J. M., Ramakers, C., Hoogaars, W. M. H., Karlen, Y., Bakker, O., van den Hoff, M. J. B., and Moorman, A. F. M. 2009. Amplification efficiency: Linking baseline and bias in the analysis of quantitative PCR data. Nucleic Acids Res. 37:e45.

50. Shoresh, M., Harman, G. E., and Mastouri, F. 2010. Induced systemic resistance and plant responses to fungal biocontrol agents. Annu. Rev. Phytopathol. 48:21-43.

51. Steele, M. R., Gitelson, A. A., and Rundquist, D. C. 2008. A comparison of two techniques for nondestructive measurement of chlorophyll content in grapevine leaves. Agron. J. 100:779-782.

52. Ton, J., Flors, V., and Mauch-Mani, B. 2009. The multifaceted role of ABA in disease resistance. Trends Plant Sci. 14:310-317

53. Ton, J., and Mauch-Mani, B. 2004. $\beta$-Amino-butyric acid-induced resistance against necrotrophic pathogens is based on ABA-dependent priming for callose. Plant J. 38:119-130.

54. Trouvelot, S., Varnier, A. L., Allègre, M., Mercier, L., Baillieul, F., Arnould, C., Gianinazzi-Pearson, V., Klarzynski, O., Joubert, J. M., Pugin, A., and Daire, X. 2008. A $\beta-1,3$ glucan sulfate induces resistance in grapevine against Plasmopara viticola through priming of defense responses, including HR-like cell death. Mol. Plant-Microbe Interact. 21:232-243.

55. Vallad, G. E., and Goodman, R. M. 2004. Systemic acquired resistance and induced systemic resistance in conventional agriculture. Crop Sci. 44:1920-1934.

56. van der Ent, S., Koornneef, A., Ton, J., and Pieterse, C. M. J. 2009. Induced resistance-orchestrating defence mechanisms through crosstalk and priming. Pages 334-370 in: Annual Plant Reviews, Volume 34: Molecular Aspects of Plant Disease Resistance. Wiley-Blackwell, Oxford.

57. Velasco, R., Zharkikh, A., Troggio, M., Cartwright, D. A., Cestaro, A., Pruss, D., Pindo, M., FitzGerald, L. M., Vezzulli, S., Reid, J., Malacarne, G., Iliev, D., Coppola, G., Wardell, B., Micheletti, D., Macalma, T., Facci, M., Mitchell, J. T., Perazzolli, M., Eldredge, G., Gatto, P., Oyzerski, R., Moretto, M., Gutin, N., Stefanini, M., Chen, Y., Segala, C., Davenport, C., Demattè, L., Mraz, A., Battilana, J., Stormo, K., Costa, F., Tao, Q., SiAmmour, A., Harkins, T., Lackey, A., Perbost, C., Taillon, B., Stella, A., Solovyev, V., Fawcett, J. A., Sterck, L., Vandepoele, K., Grando, S. M., Toppo, S., Moser, C., Lanchbury, J., Bogden, R., Skolnick, M., Sgaramella, V., Bhatnagar, S. K., Fontana, P., Gutin, A., Van de Peer, Y., Salamini, F., and Viola, R. 2007. A high quality draft consensus sequence of the genome of a heterozygous grapevine variety. PLoS ONE 2:e1326.

58. Verhagen, B. W. M., Glazebrook, J., Zhu, T., Chang, H.-S., van Loon, L. C., and Pieterse, C. M. J. 2004. The transcriptome of rhizobacteriainduced systemic resistance in Arabidopsis. Mol. Plant-Microbe Interact. 17:895-908

59. Wahid, A., Gelani, S., Ashraf, M., and Foolad, M. R. 2007. Heat tolerance in plants: An overview. Environ. Exp. Bot. 61:199-223.

60. Walters, D., Walsh, D., Newton, A., and Lyon, G. 2005. Induced resistance for plant disease control: Maximizing the efficacy of resistance elicitors. Phytopathology 95:1368-1373.

61. Walters, D. R. 2009. Are plants in the field already induced? Implications for practical disease control. Crop Prot. 28:459-465.

62. Walters, D. R., Ratsep, J., and Havis, N. D. 2013. Controlling crop diseases using induced resistance: Challenges for the future. J. Exp. Bot. 64:1263-1280

63. Yasuda, M., Ishikawa, A., Jikumaru, Y., Seki, M., Umezawa, T., Asami, T., Maruyama-Nakashita, A., Kudo, T., Shinozaki, K., Yoshida, S., and Nakashita, H. 2008. Antagonistic interaction between systemic acquired resistance and the abscisic acid-mediated abiotic stress response in Arabidopsis. Plant Cell 20:1678-1692. 